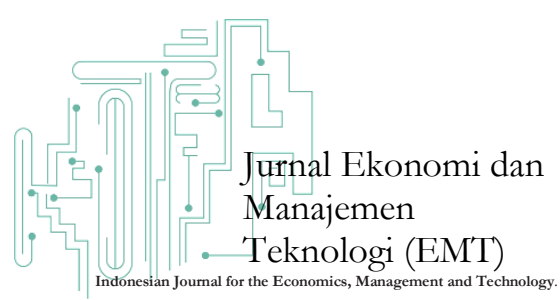

Jurnal Ekonomi dan Manajemen Teknologi, 3(2), 2019, 94-101

Available online at http://journal.lembagakita.org

\title{
Perceived Family Burden Between Caregivers of Schizophrenic Patients
}

\author{
Mihir Ranjan Nayak ${ }^{1}$, Tapasa Mallik², Sarathi Hembram³ ${ }^{3}$ Manaswini Dash ${ }^{4}$ \\ 1,2,3 Dept. of Psychiatry, MHI (CoE), SCB MCH, Cuttack, Odisha, India \\ ${ }^{4}$ JKBK Govt. College, Cuttack, Odisha, India
}

\begin{abstract}
The purpose of this study was to assess and examine the family burden among male and female nurses with schizophrenia patients. The sample population consisted of 60 male and female caregivers of schizophrenic patients selected using purposive sampling from outside patients and indoor patients, MHI, COE, SCBMCH, Cuttack. Odisha. The Family Expense Interview Schedule is applied to caregivers. The results showed that female caregivers had more family burden in all domains compared to male caregivers of schizophrenic patients.
\end{abstract}

Keywords: Family Burden, Caregivers, Schizophrenia. 


\section{Introduction}

Schizophrenia is a major mental illness that can have a broad effect on day to day functioning in social relationship and in the ability to take care of themselves. But it can also have a significant impact on the whole family, requiring substantial time, energy and money to help the family member and increasing stress and tension on a daily basis. Schizophrenia exerts a high financial and emotional cost not only from patients, but also from their families, including parents and siblings. Magliano et al. (2005) conducted a research study and find out that caregivers play an important role in supporting the family members who are suffering from psychiatric disorders besides pharmacological treatment. The quality of care given which is provided by the caregivers in the family is directly associated with the functioning of the patients who is suffering from mental illness. But these care givers daily schedules become immensely hectic because of their ill relative's incapacity and dealing with some social vices, i.e., stigma and stereotypes towards mental patients.

\section{Methodology}

Aim

The aim of the present study is to asses and examines family burden among the male and female care givers of schizophrenia patients.

\section{Objectives}

1. To assess the family burden among the male and female caregivers of schizophrenia patients.

2. To compare the family burden among the male and female caregivers of schizophrenia patients.

\section{Hypothesis of the study}

There will be no significant difference in the family burden among the male and female caregivers of schizophrenia patients.

\section{Research Design}

The study was a cross-sectional hospital based comparative study among the male and female caregivers of schizophrenia patients.

\section{Sample}

A total no of 60 male and female caregivers of schizophrenia patients were selected. The sample was further divided into 30 male and 30 female caregivers from outdoor patient and indoor patient, MHI, COE, SCBMCH, Cuttack.

Inclusion criteria for Male and Female patients with schizophrenia

1. Diagnosed schizophrenia according to DCR of ICD-10.

2. Age range $20-55$ years.

3. Both male and female patients.

4. Duration of illness must be 2 years or above.

Exclusion criteria for male and female patients with schizophrenia

1. Any history of significant physical or neurological conditions.

2. Any history of psychiatric co-morbidity.

3. Any history of Mental retardation, Epilepsy or Substance abuse.

Inclusion criteria for caregivers (Male \&Female)

1. Primary caregiver staying with patient for at least 2 years

2. The caregivers may be parents, spouse, sibling or children.

3. Age range from 20-60 years.

4. Must be educated up to primary level or above.

5. Give consent.

\section{Exclusion criteria for caregiver}

1. Any history of epilepsy, organic brain disorder or major physical illness.

2. Any history of psychiatric illness including substance dependence.

3. Any history of personality disorders or mental retardation.

4. More than one psychiatric ill patient present in the family.

\section{Tools used}

1. Socio-demographic and clinical data sheet. (Self-prepared)

General Health Questionnaire (GHQ-12; Goldberg \& William, 1988)

2. Family Burden Interview Schedule (Shaila, Pai\& Kapoor, R.L., 1981).

Description of Tools

1. Socio-demographic and clinical data sheet: It is self-structured Performa which 
contains information regarding sociodemographic variables like age, sex, religion, education, marital status, domicile and occupation and clinical details like diagnosis, age of onset, total duration of illness etc.

2. General Health Questionnaire (GHQ- 12; Goldberg \& William, 1988):

Goldberg and William developed the General Health Questionnaire-12. It is used to screen any psychiatric morbidity in healthy persons. General Health Questionnaire-12 is the short version of the original General Health Questionnaire containing 60 items for the detection of the psychiatric illness. Internal consistency of GHQ-12 was excellent. A higher degree of internal consistency was observed for each of the 12 items with Cronbach's alpha value of $0.37-0.79$, while total score was 0.70 in the population study. Test-retest correlation coefficients for the 12 items score were highly significant. It is widely used to screen for the presence of psychiatric distress. Cut of score is $\leq 3$.

3. Family Burden Interview Schedule (Shaila, Pai\& Kapoor, R.L., 1981):

This is a semi-structured interview schedule comprising of 24 items grouped under 6 dimensions:

Financial burden, Disruption of routine family activities, Disruption of family leisure, Disruption of family interaction, Effect on physical health of others, Effect on mental health of others. All the items of this scale are rated on 3point scale (viz, severe burden, Moderate burden and No burden). The validity and reliability for each item was reported to be more than 0.78 by the authors which mediates that this present schedule is reliable tool. The validity of the schedule was also assessed by corelating objective burden rating and as reported by the relatives of patients. The correlation was found to be 0.72 which can be considered significant. The Hindi translation of the schedule as applied earlier by Kumar N, Kumar, M. (2002).

\section{Procedures}

Informed consent was taken from caregivers coming to OPD and IPD by considering the inclusion and exclusion criteria. The tools were administered on the sample. Further information was collected on the basis of socio-demographic data sheet. Subsequently, those who were willing to participate in the study, was screened with general health questionnaire (GHQ) 12,). After completion of data collection, data were coded in the sheet (Master chart) and data analysis was done by using statistical package for social science (SPSS) version 16.0. Comparison of Family Burden of the male and female caregivers with schizophrenia patients was carried out using independent $t$ test. Descriptive statistics were used to get the mean scores, percentile and chi square of the socio-demographic variables.

\section{Results}

The table no. 1 shows the descriptive statistics for socio-demographic details of persons with schizophrenia. It reveals out of total 60 patients, each $50 \%$ was male and female respectively. It presented the majority $81.7 \%$ patients belonged to Hindu Religion. Similarly, the highest 38.3\% of total patients studied up to upper primary. The maximum $48.3 \%$ patients were married. The lowest $8.3 \%$ of the patients were doing private job whereas the highest $50 \%$ of the patients were doing some other job other than private job, selfemployed and unemployed. The majority $60 \%$ of the patients were belonging to the rural areas and majority $61.7 \%$ were belonging to joint family.

Table 1. Descriptive Statistics for socio demographic profile of Schizophrenia Patients

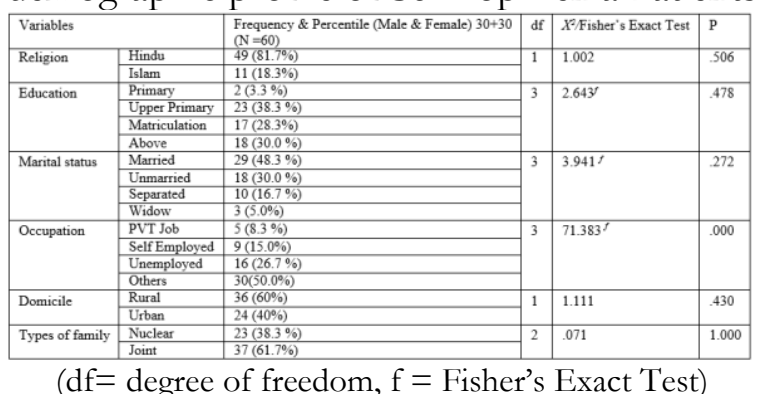

Table no-2. reveals that out of total 60 caregivers each $50 \%$ were male and female respectively. The highest $31.7 \%$ of caregivers studied up to matriculation. The majority $35 \%$ of them were self-employed. The maximum $98.3 \%$ of caregivers were married. The highest $30.0 \%$ of caregivers were brothers of the patients. The highest $60 \%$ of caregivers belonged to upper 
lower socio-economic status. The majority $55 \%$ of the caregivers had the monthly income Rs. (3908-11707).
Table no-04 shows that the comparison of family burden of male and female caregivers of persons with schizophrenia. In this present study the

Table 2. Descriptive Statistics for sociodemographic profile of male and female Caregivers of schizophrenia patients

\begin{tabular}{|c|c|c|c|c|c|}
\hline \multicolumn{2}{|l|}{ Variables } & $\begin{array}{l}\text { Frequency \& Percentile (Male \&Female) } 30+30 \\
(\mathrm{~N}=30)\end{array}$ & $\mathrm{df}$ & $X^{2} /$ Fisher's Exact Test & $\mathrm{p}$ \\
\hline \multirow[t]{4}{*}{ Education } & Primary & $12(20.0 \%)$ & \multirow[t]{4}{*}{3} & \multirow[t]{4}{*}{$13.664^{f}$} & \multirow[t]{4}{*}{.003} \\
\hline & Upper Primary & $16(26.7 \%)$ & & & \\
\hline & Matriculation & $19(31.7 \%)$ & & & \\
\hline & Above & $13(21.7 \%)$ & & & \\
\hline \multirow[t]{4}{*}{ Occupation } & PVT Job & $18(30.0 \%)$ & \multirow[t]{4}{*}{3} & \multirow[t]{4}{*}{$23.792^{f}$} & \multirow[t]{4}{*}{.000} \\
\hline & Govt. job & $4(6.7 \%)$ & & & \\
\hline & Self Employed & $21(35.0 \%)$ & & & \\
\hline & Others & $17(28.3 \%)$ & & & \\
\hline \multirow[t]{2}{*}{ Marital status } & Married & $59(98.3 \%)$ & \multirow[t]{2}{*}{1} & \multirow[t]{2}{*}{1.017} & \multirow[t]{2}{*}{1.000} \\
\hline & Unmarried & $1(1.7 \%)$ & & & \\
\hline \multirow[t]{6}{*}{ Relationship with pt. } & Father & $3(5.0 \%)$ & \multirow[t]{6}{*}{5} & \multirow[t]{6}{*}{$56.864^{f}$} & \multirow[t]{6}{*}{.000} \\
\hline & Mother & $12(20.0 \%)$ & & & \\
\hline & Brother & $18(30.0 \%)$ & & & \\
\hline & Sister & $5(8.3 \%)$ & & & \\
\hline & Wife & $13(21.7 \%)$ & & & \\
\hline & Husband & $9(15.0 \%)$ & & & \\
\hline \multirow[t]{2}{*}{ Socio Economic Status } & Upper lower & $36(60 \%)$ & \multirow[t]{2}{*}{1} & \multirow[t]{2}{*}{2.500} & \multirow[t]{2}{*}{.187} \\
\hline & Lower Middle & $24(40 \%)$ & & & \\
\hline \multirow[t]{3}{*}{ Family monthly Income } & $3908-11707$ & $23(55.0 \%)$ & \multirow[t]{3}{*}{2} & \multirow[t]{3}{*}{1.368} & \multirow[t]{3}{*}{.518} \\
\hline & $11708-19515$ & $23(38.3 \%)$ & & & \\
\hline & 19516-29199 & $4(6.7 \%)$ & & & \\
\hline
\end{tabular}

$(\mathrm{df}=$ degree of freedom, $\mathrm{f}=$ Fisher's Exact Test $)$

Table 3. Descriptive statistics for Patients Age and Caregivers age

\begin{tabular}{|c|c|c|r|r|r|}
\hline Variable & Sex & $\begin{array}{c}\text { Sample N }=30 \\
\text { Mean } \pm \text { SD }\end{array}$ & Df & $\mathrm{t}$ & $\mathrm{P}$ \\
\hline Patients Age & Male & $36.133 \pm 7.477$ & 58 & -466 & .591 \\
\cline { 2 - 4 } & Female & $37.000 \pm 6.923$ & & & \\
\hline Caregivers age & Male & $41.566 \pm 7.079$ & 58 & -737 & .464 \\
\cline { 2 - 3 } & Female & $43.233 \pm 10.173$ & & & \\
\hline
\end{tabular}

The table no-3 shows the descriptive statistics for patients and caregivers age respectively. It presents that Mean \pm SD of the age of male patients was36.133 \pm 7.477 whereas for female patients it was 37.000 \pm 6.923 . Similarly, Mean \pm SD of the age of male caregivers was41.566 \pm 7.079 whereas for the female caregivers it was43.233 \pm 10.173 . comparison of family burden of caregivers of persons with schizophrenia was done. The Mean $\pm S D$ of male and female caregivers was $(7.00 \pm 1.36)$ and $(7.80 \pm 1.24)$ respectively on financial burden. On distuption of routine family activities domain, the Mean \pm SD of male and female caregivers was $(5.53 \pm 1.50)$ and (6.70 \pm 1.34$)$ respectively. The Mean \pm SD of male and female caregivers was $(4.66 \pm 1.37)$ and $(5.73 \pm 1.22)$ respectively on disruption of routine family leisure. The Mean $\pm \mathrm{SD}$ of male caregivers

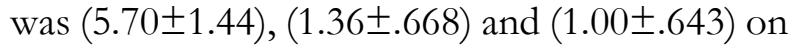
disruption of routine family interaction, effect on physical health of others and effect on mental health of others respectively whereas for female

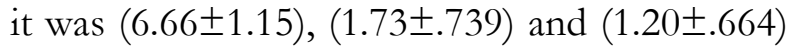
respectively on these same above three domains.

Table 4. Comparison of family Burden among the caregivers of Schizophrenia Patients

\begin{tabular}{|l|l|l|l|l|l|}
\hline \multirow{2}{*}{ FB Domains } & \multicolumn{2}{|l|}{ Caregiver Groups } & T & df & P \\
\cline { 2 - 4 } & $\begin{array}{l}\text { Male(N=30) } \\
\text { Mean } \pm \text { SD }\end{array}$ & $\begin{array}{l}\text { Female(N=30) } \\
\text { Mean } \pm \text { SD }\end{array}$ & & & \\
\hline Financial Burden & $7.00 \pm 1.36$ & $7.80 \pm 1.24$ & 2.374 & 58 & $.021^{*}$ \\
\hline Disruption of routine family activities & $5.53 \pm 1.50$ & $6.70 \pm 1.34$ & 3.171 & 58 & $.002^{*}$ \\
\hline Disruption of routine family leisure & $4.66 \pm 1.37$ & $5.73 \pm 1.22$ & 3.170 & 58 & $.002^{*}$ \\
\hline Disruption of routine family interaction & $5.70 \pm 1.44$ & $6.66 \pm 1.15$ & 2.866 & 58 & $.006^{*}$ \\
\hline Effect on physical health of others & $1.36 \pm .668$ & $1.73 \pm .739$ & 2.014 & 58 & $.049^{*}$ \\
\hline Effect on mental health of others & $1.00 \pm .643$ & $1.20 \pm .664$ & 1.185 & 58 & .241 \\
\hline
\end{tabular}

$*_{p}<0.05$ (Statistical significance at 0.05 Level) 
Discussion

Sample and sampling

The present study was conducted at the M.H.I (C.O.E), SCBMCH, Cuttack. A total number of 60 caregivers of male and female patients with schizophrenia were selected. The sample would be further divided into 30 male and 30 female caregivers from outpatient and indoor patient of MHI. It was a cross sectional hospital based comparative study. Similar study methodology was used by Swain et al., (2017), Parija, S., Yadav, A. K., Sreeraj, V. S., Patel, A. K., \& Yadav, J. (2018). Also they used purposive sampling hospital based

\section{Tools}

In the present study family burden interview schedule was used to assess perceived family burden among the caregivers of male and female patients with schizophrenia. Family Burden Interview Schedule developed by Pai\& Kapoor (1982) the Hindi translation of the schedule It is a semi-structured interview schedule comprising of 24 items grouped under 6.

\section{Dimensions}

Financial burden, Disruption of routine family activities, Disruption of family leisure, Disruption of family interaction, Effect on physical health of others, Effect on mental health of others. All the items of this scale are rated on 3point scale (viz, severe burden, Moderate burden and No burden). Similar tool was used by Swain et al., (2017), Yazici et al., (2016) and Geriani et al., (2015) to examine the family burden among the caregivers of persons with schizophrenia.

\section{Discussion on Socio-demographic profile of person with schizophrenia:}

The present study revealed that out of 60 numbers of patients each $50 \%$ was male and female respectively. It showed that Mean \pm SD of the age of male patients is $(36.133 \pm 7.477)$ whereas for female it was $(37.000 \pm 6.923)$. The majority $81.7 \%$ of patients were belonging to the Hindu religion. Similarly, the maximum $38.3 \%$ studied up to upper primary. Also it was found from this study that most of the patients i.e. $48.3 \%$ were married. The majority $50.0 \%$ of them were engaged in some other occupational activity other than self-employed and private job. The majority $60 \%$ of the patients were belonging to the rural areas and majority $61.7 \%$ were belonging to the joint family. Similar study findings were reported by Singh et al., (2012). They reported that the Mean \pm SD of the age of male patients was $(34.2 \pm 13.8)$ and for female it was $(33.6 \pm 13.01)$. The majority $67.5 \%$ studied up to primary, $36.1 \%$ up to matriculation and the rest $2.5 \%$ up to above matriculation. Majority of the patients $(87.5 \%)$ were unmarried and only $7.5 \%$ were married. The rest $5 \%$ were widow. The majority $(53.23 \%)$ of the patients were unemployed. In this study the majority $48.3 \%$ were married where in the above only $7.5 \%$ were married. This can be explained as the family members have some kind of misconception regarding the mental illness that mental illness of the patient can be cured after marriage. So majority of patients were married in this study. Also most of the patients of this study were from rural Odisha because for having better psychiatric treatment they prefer to come to MHI, COE as it is a tertiary mental health institute.

Discussion on socio-Demographic Profile of caregivers of Person with Schirophrenia:

This study revealed that out of 60 caregivers each $50 \%$ was male and female respectively. It showed that Mean \pm SD of the age of male caregivers was $(41.566 \pm 7.079)$ whereas for female it was $43.233 \pm 10.173$. The highest $31.7 \%$ studied up to matriculation and maximum $35.0 \%$ caregivers were self-employed. The majority $98.3 \%$ of caregivers were married. This study also revealed that the majority $30.0 \%$ of caregivers were brother of the patients. Also it showed that most of the caregivers $(60.0 \%)$ were belonging to the upper lower socio economic status. The maximum $55 \%$ of the caregivers had the monthly family income Rs. (3908-11707).

Similar study findings were reported by Singh et al., (2012). They reported that the Mean \pm SD of the age of male caregivers was $(52.5 \pm 16.5)$ and for female it was $(58.3 \pm 9.5)$. Out of total 40 caregivers, the majority $85.0 \%$ of caregivers studied up to primary level and the rest each $7.5 \%$ studied up to matriculation and above matriculation. $20.0 \%$ of the caregivers were engaged in Govt. job, $15.0 \%$ were self-employed and the rest $65.0 \%$ of the caregivers in some other occupational activities. The majority $87.5 \%$ 
of caregivers were father of the patients and the each $5.0 \%$ were spouse and sibling of the patients respectively. The rest $2.5 \%$ were sons of the patients.

\section{Discussion on comparison of family Burden of caregivers of the persons with Schirophrenia:}

In this present study the comparison of family burden among the caregivers of male and female schizophrenia patients was done. It showed that there was statistical significant different $(\mathrm{p}<0.05)$ in between two groups in domains of family burden like 'financial burden', 'Disruption of routine family activities', 'Disruption of routine family leisure', 'Disruption of routine family interaction', and 'Effect on physical health of others'. However, no difference could be observed in other domain like 'Effect on mental health of others' of family burden interview schedule. The present findings suggested that female caregivers are having more family burden in all domains in comparison to male caregivers of schizophrenia patients.

Similar study findings were reported by Kapur (1981). The findings suggest that both the groups, viz., male and female spouses of schizophrenia patients, showed moderate level of subjective burden, i.e., $13(52 \%)$ and 15 $(60 \%)$ male and female spouses, respectively, which was statistically found to be insignificant. Similarly, Ponangi et al., (2014) has found that burden of care was high in both subjective and objective scales and factors like female sex, middle age and severity of illness had effect on extent of burden. Swain et al., (2017) shows the level of subjective perception of the care givers towards their responsibilities. While half of the care givers of dementia patients felt that the family burden was little, nearly three quarters $(73.4 \%)$ of those caring for schizophrenia patients had similar perception. Only a small proportion of the caregivers in both the groups had no perception of family burden (i.e., 6.3\% and $12.5 \%$ for dementia and schizophrenia respectively). Overall the association between the level of subjective perception of family burden and the caregiver type was found to be statistically significant. Yusuf et al., (2009) showed a high level of caregiver burden was found in $61(47.3 \%)$ respondents. A higher level of caregiver burden was significantly associated with place of residence and family size. Analysis of responses to items on the Zarith Burden Interview (ZBI) showed that factors related to stigma, negative behaviours of the patients and financial constraints were the caregivers' three most-reported causes of burden. Overall, 97 $(75.2 \%)$ respondents indicated experiencing an enormous burden as a result of caring for their relatives.

\section{Conclusion}

The conclusion of present study was that there may be no significant difference in the family burden among the caregivers of male and female schizophrenia patients. However, in this present study significant difference was found in the family burden amongthe caregivers of male and female schizophrenia patients in the domains like financial burden, distuption of routine family activities, disruption of routine family leisure, disruption of routine family interaction and effect on physical health of others and there was insignificant difference in domain of effect on mental health of others. Also it was found that female caregivers are having more family burden in all domains in comparison to male caregivers of schizophrenia patients.

\section{References}

Awad, A. G., \& Voruganti, L. N. (2008). The burden of schizophrenia on caregivers. Pharmacoeconomics, 26(2), 149-162.

Borrell-Carrió, F., Suchman, A. L., \& Epstein, R. M. (2004). The biopsychosocial model 25 years later: principles, practice, and scientific inquiry. The Annals of Family Medicine, 2(6), 576-582.

Caring for the caregiver: Why your mental health matters when you are caring for others. Woodbridge VA 22192 USA: World Federation of Mental Health (WFMH); 2010

Chan, S. W. C. (2011). Global perspective of burden of family caregivers for persons with schizophrenia. Archives of psychiatric nursing, 25(5), 339-349. 
Dagaonkar, A., Jadhav, B., Shanker, S., Shah, B., Rajagopal, L., Gopinathan, A., \& Dhavale, H. (2013). Perception of burden by caregivers of patients with schizophrenia. Archives of Mental Health, 14(2), 141-141.

Goldberg, D. P. (1988). User's guide to the General Health Questionnaire. Windsor.

Gururaj, G., Girish, N., \& Isaac, M. K. (2005). Mental, neurological and substance abuse disorders: Strategies towards a systems approach. Burden of Disease in India, 226.

Kaur, N. (2014). Caregiving burden and social support among caregivers of schizophrenic patients. Delhi Psychiatric Journal, 17(2), 337-342.

Kim, M. (2016). Understanding the Etiology and Treatment Approaches of Schizophrenia: Theoretical Perspectives and Their Critique. Open Journal of Psychiatry, 6(04), 253.

Kumari, S., Singh, A. R., Verma, A. N., Verma, P. K., \& Chaudhury, S. (2009). Subjective burden on spouses of schizophrenia patients. Industrial psychiatry journal, 18(2), 97.

Leung MD, D. A., \&Chue MRC Psych, D.

P. (2000). Sex differences in schizophrenia, a review of the literature. ActaPsychiatrica Scandinavica, 101(401), 3-38.

Loganathan, S., \& Murthy, R. S. (2011). Living with schizophrenia in India: gender perspectives. Transcultural psychiatry, 48(5), 569-584.

Magliano, L., Fiorillo, A., De Rosa, C., Malangone, C., Maj, M., \& National Mental Health Project Working Group. (2005). Family burden in long-term diseases: a comparative study in schizophrenia vs. physical disorders. Social science \& medicine, 61(2), 313-322.
Mandelbrote, B., \&Folkard, S. (1961). Some problems and needs of schizophrenics in relation to a developing psychiatric community service. Comprehensive Psychiatry, 2(6), 317-328.

Melchert, T. P. (2011). Foundations of professional psychology: The end of theoretical orientations and the emergence of the biopsychosocial approach. Elsevier.

Ooms, T., \&Preister, S. (1988). A Strategy for strengthening families: using family criteria in policy making and program evaluation: a report. AAMFT Research and Education Foundation.

Pai, S., \&Kapur, R. L. (1981). The burden on the family of a psychiatric patient: development of an interview schedule. The British Journal of Psychiatry, 138(4), 332335.

Parija, S., Yadav, A. K., Sreeraj, V. S., Patel, A. K., \& Yadav, J. (2018). Burden and Expressed Emotion in Caregivers of Schizophrenia and Bipolar Affective Disorder Patients: A Comparative Study. MAMC Journal of Medical Sciences, 4(2), 68.

Raguram, R., Raghu, T. M., Vounatsou, P., \& Weiss, M. G. (2004). Schizophrenia and the cultural epidemiology of stigma in Bangalore, India. The Journal of nervous and mental disease, 192(11), 734-744.

Sadock, B. J., \&Sadock, V. A. (2011). Kaplan and Sadock's synopsis of psychiatry: Behavioral sciences/clinical psychiatry. Lippincott Williams \& Wilkins.

Sartorius, N., \& Schulze, H. (2005). Reducing the stigma of mental illness: a report from a global association. Cambridge University Press.

Sie, M. (2011). Clinical Focus- SchizophreniaClinical features and diagnosis. Clinical Pharmacist, 3(2), 41. 
Sinason, V. (1992). Mental handicap and the human condition. London: Free Association Books.

Srivastava, S. (2005). Perception of burden by caregivers of patients with schizophrenia. Indian Journal of Psychiatry, 47(3), 148.

Swain, S. P., Behura, S. S., \& Dash, M. K. (2017). A comparative study of family burden and quality of life between caregivers of schizophrenia and dementia patients. International Journal of

Community Medicine And Public Health, 4(6), 2021-2026.

Thara, R., \& Joseph, A. A. (1995). Gender differnces in symptoms and course of schizophrenia. Indian journal of psychiatry, 37(3), 124.

Thara, R., \&Rajkumar, S. (1992). Gender differences in schizophrenia: results of a follow-up study from India. Schizophrenia Research, 7(1), 65-70.
Thimmajja, S. G., \& Rathinasamy, E. V. L. (2018). A Study to Assess the Level of Caregivers' Burden and Associate with the Socio Demographic Factors of Caregivers of Patients with Schizophrenia-A Cross Sectional Study. International Journal of Indian Psychology, Volume 6, Issue 1, (No. 5), 6, 37 .

Thornicroft, G., Rose, D., \&Kassam, A. (2007). Discrimination in health care against people with mental illness. International review of psychiatry, 19(2), 113-122.

Nayak, M. R., Mallik, T., Hembram, S., \& Dash, M. (2020). Perceived Family Burden among the Male \& Female Caregivers of Schizophrenia Patients-A Comparative Study in Eastern India. International Journal of Research and Review, 7(1), 93100.

Yusuf, A. J., Nuhu, F. T., \& Akinbiyi, A. (2009). Caregiver burden among relatives of patients with schizophrenia in Katsina, Nigeria. South African Journal of Psychiatry, 15(2). 